Global Conferences Series:

Social Sciences, Education and Humanities (GCSSSEH), Volume 6, 2020

International Conference Fakultas Tarbiyah dan Keguruan Universitas Islam Negeri Imam Bonjol Padang (ICFTKUINIBP) 2020

DOI: https://doi.org/10.32698/icftk391

\title{
ESP and Mardeka Belajar in Islamic Higher Education English Learning
}

\section{ESP dan Mardeka Belajar pada Pembelajaran Bahasa Inggris Perguruan Tinggi Islam}

\author{
Elismawati $^{\mathrm{a}}$, Hadeli ${ }^{\mathrm{a}}$, Zulvia Trinova ${ }^{\mathrm{a}}$, Hidayat Al Azmi \\ ${ }^{a}$ Universitas Islam Negeri Imam Bonjol, Padang, Indonesia \\ E-mail: elismawati_1957@yahoo.com
}

\begin{abstract}
The ability to master a foreign language is a student's need to compete at the international level. For this reason, universities are required to provide opportunities for lecturers to choose a lecturer in teaching English at tertiary institutions. In several studies it was found that students of Islamic Higher Education have the motivation and desire students who are strong enough to learn foreign languages but only a small proportion of them successfully master both international languages simultaneously (Arabic and English). The ESP (Materials, Methods and Needs Analysis) approach to the English Subject This is because English in tertiary institutions is complex and requires efforts that also involve many parties. The learning process in this skill requires a structured process and adequate time. Based on cognitive theory in learning, Merdeka Belajar provides the widest opportunity for students to control and carry out the learning process by involving metacognitive, motivational, and attitudinal aspects in achieving learning goals. For this reason, an ESP product is needed which aims to help students implement an independent learning system because one form of implementing this approach is the creation and selection of material methods based on student needs (limitations, desires, and interests).
\end{abstract}

Keywords: ESP, mardeka belajar

\section{INTRODUCTION}

Kemajuan ilmu pengetahuan yang disertai oleh kemajuan industry yang berimbas pada bidang perekonomian. Saat ini dunia ekonomi global membutuhkan personel yang mampu berfikir dan bertindak dengan cepat, kreatif, memiliki kemampuan komunikasi dan keterampilan sosial yang baik, kemampuan tim kerja, kemampuan untuk belajar secara mandiri dan beradaptasi dengan perubahan serta navigasi pengetahuan (Bates dan Sangrà 2011). Untuk bisa memiliki daya saing pada skala nasional dan internasional, mahasiswa dalam setiap perguruan tinggi harus memiliki kemampuan bahasa asing yang baik. Pada umumnya bahasa asing yang diajarkan pada sebuah perguruan tinggi adalah bahasa Inggris. Pembelajaran bahasa Inggris pada perguruan tinggi memiliki karakter dan pedekatan yang berbeda dengan pembelajaran bahasa pada level sekolah karena memiliki tujuanyang sangat berbeda. Adapun tujuan dari pembelajaran bahasa Inggris pada pada level universitas adalah membantu mahasiswa untuk memiliki kemampuan bahasa Inggris pada tingkat mahir dan pada akhirnya dapat membantu mereka untuk memperkaya ilmu pada bidang mereka masing masing serta yan tidak kalah pentingnya adalah untuk membantu mereka untuk meningkatkan kompetensi dalam berkarir pada dunia pekerjaan. Menyikapi hal ini, program studi memiliki matakuliah bahasa Inggris sebagai matakuliah umum dengan tujuan membantu mahasiswa menguasai bahasa inggris yang sesuai dengan kebutuhan yang mereka miliki.Beberapa penelitian mengungkapkan bahwa pembelajaran bahasa Inggris pada perguruan tinggi masih belum mengarah pada kebutuhan bahasa asing yang tersirat dalam tujuan masing masing Program Studi di perguruan tinggi.Hal ini disebabkan karena dosen bahasa Inggris pada perguruang tinggi tidak dibekali oleh keahlian ESP (Kusni, 2013) sehingga mereka memiliki keterbatasan. 
Hal ini berarti bahwa sebagian besar pembelajaran bahasa Inggris di perguruan tinggi belum maksimal dan pada saat need analysis dilaksanakan, hasil dari analisis tersebut belum digunakan secara maksimal dalam desain pembelajarana bahasa Inggris. Hal ini menyebabkan materi dan prosedur yang ada pada saat mengajarkan bahasa Inggris belum sepenuhnya menyentuh keinginan, keperluan dan menutupi keterbatan aspek dan skill bahasa Inggris yang dimiliki oleh mahasiswa tersebut.Dengan adanya kebijakan merdeka belajar maka peluang untuk mengembangkan dan menjamin keberlangsung penerapan ESP pada perguruan tingga akan terbuka luas karna pringsip pembejaran Bahasa Inggris dengan menpggunakan pendekatan ESP memilik kecocokan dengan pringsip merdeka belajar. Pringsip kebebasan belajar yang sangat mempertimbangakan aspek siswa atau mahasiswa sangat menfasilitasi penerapan pendekatan ESP karena metode dan meteri yang akan dipakai sangat terbantung pada kondisi dan kebutuhan aspek, skill dan bahasa yang dimiliki oleh mahasiswa. Dalam upaya mewujudkan Visi Internasional berbagai perguruan tinggi Islam diIndonesia maka penerapan matakulian Bahasa Inggris yang berdasarkan pada tujuan khusus merupakan salah satu upaya untuk membantu Visi tersebut terwujud dimasa yang akan datang. Dengan berlatarbelakang kampus, pendidikan dan keilmuan Keislaman maka para dosen dan mahasiswa harus mampu untuk menjadikan ilmu yang mereka hasilkan berdampak pada negara dan dunia Internasional.

Dengan mempertimbangkan paparan diatas maka makalah ini dapat memberikan penjelasan tentang keterkaitan desain pembelaharan Bahasa Inggris ESP dengan karakter dan pringsip-pringsip belajar Merdeka dan penerapannya pada Perguruan Tinggi Islam.

\section{METODE}

Metode yang digunkan adalah Field Research, yakni dengan memaparkan dan menggambarkan keadaan atau fenomena secara jelas berdasarkan situasi yang terjadi. Pada penelitian deskriptif dapat di artikan sebagai penelitian yang berusaha untuk menuturkan pemecahan masalah yang diselidiki dengan menggambarkan keadaan objek penelitian yang ada pada saat sekarang berdasarkan fakta-fakta atau data-data yang ada. Menurut Arikunto penelitian deskriptif tidak dimaksudkan untuk menguji hipotesis tertentu tetapi hanya menggambarkan apa adanya tentang suatu gejala variabel atau keadaan yang sebenarnya. (Suharsimi, 1990:310)

Menurut Sugiyono penelitian kualitatif adalah metode penelitian yang digunakan untuk meneliti pada kondisi obyek yang alamiah, (sebagaimana lawannya adalah eksperimen) dimana peneliti adalah sebagai instrumen kunci, teknik pengumpulan data dilakukan secara trianggulasi(gabungan), analisis data bersifat induktif dan hasil penelitian kualitatif lebih menekankan makna dari pada generalisasi. (Sugiyono, 2015:1).

\section{HASIL DAN DISKUSI}

\section{English for Specific Purposes (Bahasa Inggris untuk tujuan Khusus)}

ESP (English for Specific purposes) atau Bahasa Inggris untuk tujuan khusus merupakan pendekatan pengajaran Bahasa Inggris di mana siswa mempelajari bahasa melalui konten mata pelajaran di bidang spesialisasi. Sebagai sebuah pendekatan yang ditawarkan dalam pembelajaran bahasa Inggris, ESP berfokus pada tujuan tertentu (Tom Hutchinson \& Alan Waters Lancaster, 1986). Pendekatan ini diciptakan karena semakin berkembangnya permintaan skill berbahasa Inggris di dunia kerja seiring dengan kemajuan indutri dan tekhnologi. Dengan Pertumbuhan bisnis yang semakin pesat menjadikan pelaku dunia usaha membutuhkan kemampuan untuk berkomunikasi dalam skala internasional, maka kebutuhan akan penguasaan bahasa asing juga berkembang pesat. Tidak hanya dalam hal metode dan materi ESP dan EGP (English for General Purposes) memiliki perbedaan yang sangat mendasar dari aspek tujuan pembelajaran. Untuk itu aspek - aspek yang sangat perlu untuk dipertimbangakan adalah aspek kebutuhan, tujuan, dan motivasi yang dimiliki oleh siswa atau mahasiswa (Lamri, 2016). Evans dan Tony (1997) merumuskan beberapa poin yang menjadikan ESP berbeda dengan General English atau bahasa Inggris Umum.Di samping bertujuan untuk memenuhi kebutuhan bahasa Inggris mahasiswa, pendekatan ini juga menggunakan metode tertentu serta aktifitas yang terbagantung pada keilmuan tertentu. Pendekatan ini sangat memberi perhatian yang pengusaan grammar, lexical (variasi kosakata), kosa kata khusus, skill, teks dan jenis teks. Dalam hal variable, ESP didisain berdasarkan disiplin ilmu tertentu yakni dengan menggunakan situasi khusus, dan dirancang untuk mahasiswa yang memiliki tingkat kemahiran bahasa yang tinggi baik pada perguruan tinggi maupun yang berada pada lembaga - lembaga tertentu. Pendekatam ESP menyeimbangkan subjek dan penyajian bahasa Karen guru (dalam hal ini dosen) memberikan pengetahuan yang benar benar dibutuhkan oleh mahasiswa dan ditungkan dalam benuk materi. Hal dapat membatu mereka untuk belajar dengan lebih cepat. Melalui ESP mahasiswa tidak hanya diajarakan bahasa akan tetapi bidang ilmu yang mereka miliki. 
Hal ini berarti mereka mendapatkan dua hal secara bersamaan skil berbahasa inggris dan pengetahuan yang relevant dengan bidang mereka.

Dalam upaya mengembangkan materi ESP, praktisi seharusnya memilih materi yang berdasarkaan analisis kebutuhan, dan disain silabus yang berdasarkan isi mata kuliah. Materi yang tepat dapat memberikan stimulus dalam belajar dan menjadi faktor yang motivasi. Materi ajar merupakan bagian yang diambil dan disusun ulang untuk disesuaikan dengan kebutuhan, kemampuan seerta ketertarikan siswa pad pelajaran (Graves, 1996). Pada umumnya, guru yang mengajarkan ESP hanya menggunakan buku yang sudah ada daripada membuatnya dikarenakan mereka bukan para pakar.

\section{Pembelajaran Bahasa Inggris di Indonesia}

ESP di lingkungan Perguran Tinggi (PT) merupakan mata kuliah wajib bagi setiap jurusan/ prodi di perguruan tinggi, demikian juga Pada walaupun pada beberapa program studi menggunakan bahasa Inggris sebagai bahasa pengantar, namun sebagian besar program studi ada pada perguruan tinggi di Indonesia masing menggunakan bahasa Indonesia sebagai bahasa pengantar sehingga bahasa Inggris masih merupakan matakuliah terpusah dari matakuliah keilmuan lainnya.

Kusni ( 2006) menggambarkan bahwa dalam struktur kurikulum PT, pada awalnya, MK-BING hanya termasuk ke dalam kelompok mata kuliah dasar umum (MKDU) dengan bobot 2 SKS dan berisi bahasa Inggris umum.Kerancuan pemahaman terhadap MK ini sebagai bahasa Inggris umum atau bahasa Inggris untuk tujuan khusus berlangsung cukup lama hingga digaungkannya otonomi yang memberlakukan istilah kurikulum lokal dan kurikulum nasional.Pemberlakuan kedua kurikulum ini memungkinkan setiap PT untuk menyusun kurikulum sendiri. Pergeseran memberi dampak bagi berubahnya perlakuan terhadap mata kuliah BING, dari yang umum kepada ESP. Ada beberapa PT yang sudah memberi tajuk yang mencirikan bahwa MK BING bukan lagi berisi bahasa Inggris umum melainkan ESP seperti English for International Relations, Bahasa Inggris Hukum, Bahasa Inggris Kimia, Bahasa Inggris Teknik, dan berbagai tajuk ESP lainnya. Variasi ini tidak hanya terjadi pada kelompok dan tajuknya saja, melainkan juga pada statusnya (wajib dan pilihan), jumlah mata kuliahnya (1-4 buah), jumlah total sks-nya (2-12 sks), perancangannya, pelaksanaannya, dan evaluasinya.

Dalam upaya menjawab tantangan dunia kerja maka pihak perguruan tinggi berupaya untuk merespon permitaan dunia kerja yang mengharuskan para tamatan perkuliahan untuk mempu bersaing dalam skala internasional. Dengan menawarkan matakuliah yang membantu para mahasiswa dalam meningkatkan kemahiran skill berbahasa asing dengan menggunakan meteri yang sesuai dengan bidang dan kertarikan yang mereka miliki. Sehingga dengan konsep ini maka mahasiswa diharapkan untuk dapat menggunakan bahasa Inggris langgu dengan kontek keilmuan yang mereka miliki.

Pada beberapa prodi, khusus pada jenjang S2 dan s3, disamping bahasa Inggris untuk tujuankeilmuan, pihakperguruan mengarahkan pembelajaran bahasa Inggris untuk meningkatkan kemampuan mahasiswa dalam menjawab pertanyaan pada Test TOEFL sebagai salah satu persyaratan perguruan tinggi. Pada jenis pembelajaran ini mahasiswa dituntut agar mampu menjawab tesrt sebaik mungkin sehingga proses belajar bahasa Inggris hanya berfokus pada pembahasan soal dan bagaimana menjawab dengan benar. Akan tetapi dual benefit (keuntungan ganda) dapat terjadi dalam pembelajaran bahasa Inggris di perguruan tinggi. Mata kuliah ESP yang mereka tempuh ketika dalam masa studi S1 mereka sekaligus bisa berperan ganda mempersiapkan mereka mendapatkan kecakapan lepas kuliah untuk kepentingan pekerjaan mereka. Karakteristik ESP yang unik, yaitu tujuannya yang menyesuaikan keperluan pembelajar sangatlah cocok untuk menunjang tercapainya peran ganda ini. Dual benefit yang dapat diberikan oleh mata kuliah ESP ini akan tercapai maksimal jika tantangan-tantangan pelaksanaan ESP dapat diatasi, yaitu pada aspek pengajar, materi, fasilitas, kebijakan universitas, serta mahasiswa pembelajar ESP (Kusumaningputri, 2008). Nur (2018) menyimpulkan bahwa sejumlah perguruan tinggi diIndonesia tidak menerapkan ESP dalam pembelajaran bahasa di perkuliahan. Dengan menyadari urgensi penerapan ESP yang mencakup English for Academic Purposes (EAP) dan pembelajaran bahasa Inggris yang berorientasi pada kepentingan profesi atau pekerjaan yang dikenal dengan English for Occupation (EOP), ke depan diharapkan hasil kajian ini dapat melengkapi gagasan dalam kajian-kajian sebelumnya dalam rangka kajian mata kuliah bahasa Inggris secara komprehensif di PT (non-English majors) yang mengintegrasikan kepentingan spesifikasi bidang keilmuan dan bahasa Inggris secara akademik.

\section{ESP dan Merdeka Belajar}

Dalam mengupayakan hasil belajar yang maksimal pada perguruan tinggi setiap memiliki cara yang berbeda. Pada saat ini, pemerintah Indonesia beberapa waktu terakhir telah mencanangkan program merdeka belajar pada hamper seluruh tingkatan pendidikan. Walaupun sedang menunggu dasar peraturan yang dapat 
menaungi program ini, pada kenyataanya sudah byang perguruan tinggi yang sudah dan sedang merespon kebijakan ini. Bentuk belajar mandiri ini meminta siswa untuk mencari atau menciptakan upaya latihan yang dapat memaksimalkan hasil belajar. Akan tetapi penerapan model ini memiliki berbagai bentuk keterbatasan dalam penerapannya di negara - neagara Asia seperti Indonesia. Pada dasarnya, kebijakan pemerintah ini sudah memiliki landasan teori dan telah diterapkan pada berbagai negara di belahan dunia pada semua bidang dan mata kuliah.

Salah satu penerapan kebijakan ini adalah EIS (English Independent Study) dimana siswa atau memiliki kemampuan dalam bekerja di luar pembelajaran kelas dalam upaya meningkatkan kemampuan bahasa Inggris tanpa berdasarkan instruksi spesifik atau tugas yang diberikan oleh guru/ dosen. Dalam kaitannya dengan dengan pringsip pembelajaran ESP, merdeka belajar memiliki materi dan aktifitas yang fleksibel yang cocok dan dapat dinikmati oleh siswa. Untuk dapat mewujudkanya dengan baik, maka hal pertama yang harus diberikan kepada siswa adalah pelatihan yang bertujuan untuk memilih materi dan aktifitas pembelajaran mereka. Hal ini erat kaitannya dengan teori yang disampaikan oleh Krashen (1982) bahwa guru atau dalam hal ini adalah dosen tidak hanya memberikakn materi dalam belajar tapi juga harus menawarkan perangkat dan strategi untuk membantu siswa dalam melanjutkan pembelajaran serta meningkatkan kemampuan mereka diluar kelas. Kelas belajar mandiri berfokus pada upaya membantu dalam menemukan potensi yang dimiliki oleh mahasiswa yang dapat diterapkan pada lingkungannya atau untuk menciptakan kesempatan untuk melakukan latihan mandiri, dan yang kedua adalah agar mereka dapat melaksanakan bentuk latihan yang efektivf dengan berdasarkan pada pringsip - pringsip serta strategi merdeka belajar itu sendiri. Crabbe (1993) menjelaskan bahwa pelajar mandiri belajar menggunakan fikiran mereka, dengan tidak mempedulikan tempat dimana mereka berada. Crabbed juga menambahkan bahwa pelajar yang berhasil dalam mencapai peningkatan dalam pembelajaran adalah mereka yang mampu memilih dan menggunakan cara belajar yang paling cocok bagi diri mereka baik di dalam atau diluar kelas. Dengan kata lain, selain pembelajaran dikelas siswa seharusnya dibantu dalam menemukan potensi mereka dengan melatih sensitifitas akan bahasa Inggris yang mereka temui di lingkungan sekitar.

Menciptakan expose bahasa Inggris dapat ditigkatkan dengan memperkenalkan bahasa Inggris pada linkungan masing- masing. Hal yang dapat dilakukang sebagai contoh dari cara menemukan potensi yang dimiliki oleh mahasiswa adalah dengan mengetahui minat atau hobi membaca. Apabila selama ini mereka membaca dalam bahasa pertama, maka ada kemungkinan besar mereka memiliki cara belajar mandiri berbahasa Inggris dengan membaca buku seperti novel. Disamping menemukan Englis expose yang mereka miliki para mahasiswa juga harus diberikan pembekalan tentang berbagai macam strategi dan cara belajar mandiri yang efektif.

Salah satu cara yang sangat direkomendasikan dalam mengadopsi prinsip belajar mandiri adalah dengan menerapkan latihan Extensive Reading dimana mahasiwa dapat memilih materi latihan membaca (reading) dengan melakunya sebanyak mungkin. Sehingga beberapa pringsip cara belajar Belajar Mandiri Bahasa Inggris dapat dirangkum menjadi: 1) Pentingnya ketersediaan sumber belajar yang banyak. Pada poin ini, mahasiswa harus mampu mencari dan menciptakan explorasi sebanyak mungkin serta melakukan latihan mandiri sebanyak mereka bisa. Dalam penerapannya, mereka dapat mendapatkan sumber belajar dari lingkungan mereka sendiri seperti menggunakan media elektronik dan digital, video, TV dan social media. 2) Selain itu mahasiswa juga dapat memilih materi belajar yang mereka sukai sehingga mereka akan dapat menikmati proses belajar selama menerapkan belajar mandiri. 3) Pringsip lain yang dapat dirangkum adalah adanya peran comprehensible input (input bahasa yang bisa di pahami) dan output yang juga memilik peranan yang sangat penting. Dalam penerapanya, mahasiswa memilih sumber latihan yang tidak sulit dan juga tidak begitu mudah dan menyeimbangkan antara penggunaan input dan output.4) Prinsip yang terakhir adalah membekali mahasiswa dengan berbagai macam strategi belajar agar mereka dapat menggunakan strategi- strategi yang sesuia dan dapat mereka gunakan dengan efektif. Wong dan Nunan (2011) mengidentifikasi siswa belajar bahasa Inggris yan telah menerapakan belajar mandiri secara efektif dan aktif dalam menerapkan pendekatan belajar mereka. Temuan dari penelitian ini mengungkapkan bahwa lama waktu belajar sangat menentukan efektifitas belajar mandiri. Chamot (2005) juga membuat tinjauan dari dua buah studi yang berkaitan dengan bagaimana mengajarkan strategi dapat meningkatkan kemandirian belajar siswa. Studi ini membuktikan bahwa siswa yang diajarkan strategi belajar bahasa memiliki peningkatan kemampuan bahasa Inggris secara signifikan dibandingkan siswa tidak diajarkan. Yanren (2007) dalam penelitiannya terhadap beberapa pemenang lomba debat Bahasa Inggris yang dilaksanakan di Cina. Penelitian ini menemukan bahwa para pemenang lomba tersebut menerapkan belajar mandiri di luar kelas dengan durasi waktu yang cukup lama dengan meniru dan mengingat dialog yang ada pada buku dan film favorit mereka. Dalam penelitian yang lain, Lux (2012) menyimpulkan bahwa pada saat siswa melaksanakan 
pembelajaran mandiri diluar kelas mereka sangat membutuhkan panduan yang efektive agar dapat meningkatkan kamahiran bahasa asing yang sedang mereka pelajari.

\section{Penerapan Merdeka Belajar dam Pembelajaran Bahasa Inggris di Perguruan Tinggi Islam Target Need}

Dalam membuat desain dalam pembelajaran ESP, maka hal yang pertama yang harus dipertimbangkan adalah keperluan untuk mempelajari bahasa Ingggris. Dalam kontek perguruan tinggi Islam, maka bahasa Inggris dipelajari untuk kepentingan memmahami teks dan bacaan keaagamaan seperti hukum Islam, Hadis, uejarang Islam, Pendidikan Islam, Ekonomi Islam dan berbagaimacam sumber bacaan yang berkaitan dengan studi keIslamam. Adapun kegunaan dari penguasaan text ini adalah untuk menjadikankan merekan mahasiswa kampus Islami yang mampu membagikan pemikiran dan ide Keislaman mereka ke dunia Internasional dalam bentuk buku, jurnal, makalah dan berbagai macam tulisan lainya yang sesuai dengan bidang keIslaman yang mereka miliki. Dalam mewujudkannya, mereka akan bekolaborasi dengan teman, dosen dengan tetap memperhatikan level penggunaan bahasa, keterbatan dan keinginan yang mereka miliki agar pembelajaran ESP dapat dilaksanakan dengan lancar.

\section{Learning Need (Kebutuhan)}

Setelah mengetahui target kebutuhan dalam pembelajaran bahasa Inggris pada perguruan tinggi Islam. Maka kebutuhan belajar dari para mahasis juga merupakan langkang yang dapat dilaksanakan. Adapun indikator dari kebutuhan ini adalah a) alasan mereka intuk mempelajari bahasa Inggris (apakah untuk status, pendapatan, atau karir), b) aspek bahasa Inggris yang akan menjadi prioritas untuk ditingkatkan, c) cara belajar yang disukai (latabelakang, konsep belajar, teknik) yang cocok.

Selain dari beberapa poin diatas, sumber belajar, identitas dan kontek pembelajaaran ESP juga dapat dipertimbangakan dalam desain ESP. Sumber belajar terdiri dari pengajar yang profesional, sikap, pengetahuan dan sikap pengajar berkaitan dengan isi dari subjek pembelajaran, materi, peralatan, kesempatan untuk melaksnakan akativitas diluar. Identitas Siswa mengacu pada umur, jenis kelamin, kewarganegaraan, apa yang sudah mereka tahu berkenaan dengallan bahasa Inggris, subjek yang mereka pelajari, ketertarikan mereka, bagaimana latarbelakang social budaya yang mereka miliki, style belaja apa yang mereka miliki, bagaimana sika mereka terhadap bahasa Inggris. Konteks mengacu pada setting (tempat) dan Waktu pembelajaran ESP akan dilaksanakan: di tempat yang menyenangkan, membosankan, ribut, dingan dan lainya. Waktu juga bisa mengacu pada pembelajaran setiap hari, sekali seminggu, full time- Part time, memiliki kebutuhan yang sama dengan teman atau Pre need.

\section{SIMPULAN}

Pembelajaaran bahasa Inggris dengan Pendekatan ESP pada perguruan tinggi memiliki kaitan yang sangat erat dengan konsep Merdeka Belajar karena mahasiswa dituntut untuk memiliki kemandirian belajar agar dapat memenuhi kebutuhan peningkatan kemampuan bahasa inggris sebagaimana yang telah dirumuskan oleh perguruan tinggi. Dalm menerapkannya, Baik mahasiswa memiliki kebebasan dalam memilih materi dan metode belajar berdasarkan Need Analysis yang merupakan karakter utama dri ESP. Dalam kontek pembelajaran bahasa Inggris di perguruan Islam, kebutuhan bahasa Inggris di bidang keagamaan harus menjadi prioritas utama dalam upaya mendesain materi dan silabus perkuliahan.

\section{REFERENSI}

Chamot, A. U. (2005). Language learning strategy instruction: Current issues and research. Annual Review of Applied Linguistics, 25, 112-130

Crabbe, D. 1993. Fostering Autonomy from Within the Classroom: The Teacher's Responsibility. System, 21(4)

Dudley-Evans, Tony. 1998. Developments in English for Specific Purposes: A multi-disciplinary approach. Cambridge University Press. (Forthcoming)

Graves, K. 1996. Teachers as Course Developers. Cambridge: Cambridge University Press. Hutchinson, Tom, and Alan Waters. 1991. English for Specific Purposes: A LearningCentered

Approach. Cambridge: Cambridge University Press

Krashen, S. 1982. Principles and Practices in Second Language Acquisition. Oxford, UK: Pergamon. 
Parole: Journal of Linguistics and Education, 7 (2), 2017, 74-79 Available online at: http://ejournal.undip.ac.id/index.php/parole Needs Analysis on the Problems of Islamic Economics Students in Learning ESP at State College of Islamic Studies (STAIN) Pekalongan Jaya

Kusumaningputri, R. 2008. Pengembangan Materi ESP untuk Mahasiswa Jurusan Sastra Sejarah. Fakultas Sastra. Universitas Jember: Lemlit Universitas Jember

Kusni. 2004. Model perancangan mata kuliah ESP di perguruan tinggi (Unpublished dissesrtation). Jakarta: Universitas Indonesia.

Kusni. 2006. Tingkat Penguasaan Bidang Studi Mahasiswa oleh Dosen ESP pada Perguruan Tinggi Negeri dan swasta di Sumatera Barat' (Research Report). Padang: Universitas Negeri Padang.

Nur, M. 2018. Penerapan ESP di Perguruan Tinggi Umum (non english majors) Melalui Pendekatan ContentBased Instruction-CBT (CBT Application at Nonenglish Majors of Higher Education through CBT Approach). Mabasan. Vol. 12, No. 1

Lux, H. 2012. Independent learning for language students. Kwansei Gakuin University Humanities Review, $17,59-67$.

Wong, L. C., \& Nunan, D. (2011).The learning styles and strategies of effective language learners. System, 39, 144-163. http://dx.doi.org/10.1016/j.system.2011.05.004

Yanren, D. 2007. Text memorization and imitation: The practices of successful Chinese learners of English. System. 35(2) 